\title{
Mobility of Metals from Drill Cuttings
}

\author{
Justyna Kujawska* and Wojciech Cel
}

Department of Environmental Protection Engineering, Lublin University of Technology, 40B Nadbystrzycka Street, Lublin, Poland

\begin{abstract}
Forecasting threats resulting from the presence of heavy metals in various elements of the environment plays an important role in environmental studies. Metals in solid environmental samples are found in many forms and phases that differ in respect of mobility, bioavailability and toxicity. Pollution from deposited drilling wastes can penetrate into the environment, particularly the heavy metals may be released to the environment through rainfalls. Rainfalls may alter the $\mathrm{p}^{\mathrm{H}}$, redox conditions and may lead to migration of metals in surface and ground waters. The aim of the study was to determine whether drill cuttings contain metal forms capable of migration in aquatic and soil environment, which would increase their availability for flora and fauna.
\end{abstract}

\section{Keywords: Drill cuttings; Heavy metals; Mobility}

\section{Introduction}

Recent developments in Poland have led to a growing interest in exploration of gases from alternative sources. The exploration and exploitation of these resources is inseparably connected with producing certain extraction wastes, e.g. drill cuttings and spent drilling fluid. According to the waste catalogue, these wastes are classified as group 0105 [1]. The composition of drilling wastes is diversified and mainly depends on the type of drilling fluids applied. Wastes in Poland are presently predominantly stored or used in road engineering [2]. Unfortunately, the available data on the impact of the stored wastes on the environment is limited. Presence of hydrocarbons and heavy metals in drilling wastes constitutes a problem for the natural environment, as heavy metals do not undergo biological processes and are retained by the environment. Deposited metals may percolate to water or soil and exert a negative impact on the development of organisms in contaminated habitats. Apart from the environmental factors, the intensity of the process in question is determined by the forms of metals and the types of bonds with solid phase components [3]. Chemical fractionation consists in consecutive extractions with solutions, conducted at an increasing leaching rate, and is a commonly applied solution for determining the share of forms and fractions constituting the total content of a given metal in solid samples. Sequential extraction analysis is frequently employed in the assessment of mobility and potential impact of substances on the environment. BCR is a commonly utilized method of sequential extraction for distinguishing the following fractions: exchangeable, reducible, oxidizable (bound to organic matter), and residual. In line with the BCR method procedure, heavy metals mobility is connected with the solubility of their forms and decreases with the consecutive steps of sequential extraction; ion exchange is the most mobile form of metals, whereas the residual form - the least [4]. Metals released from the ion-exchange fraction are highly-available for uptake. The reducing fraction comprises elements absorbed or co-precipitated with $\mathrm{Fe}$ and $\mathrm{Mn}$ oxides, is characterized by medium mobility and activates under reducing conditions. The oxidizable fraction includes the organic fraction metals and exhibits medium mobility; however, it is also characterized by long-lasting bioavailability, which activates under oxidizing conditions. The residual fraction includes metals strongly bound to the solid phase, is very stable, and metals of this fraction are not available to plants [5].While a vast body of literature describes the procedure of sequential extraction of sludge and soils, the application of extraction in drilling waste can seldom be found. The aim of the study was to determine whether the drill cuttings contain forms of metals capable of migration in aquatic and soil environment, which thus could become easily available to flora and fauna.

\section{Research Methodology}

The tests were conducted on drill cuttings sample material obtained from the Maćkowice well, where potassium/polymer drilling fluid was utilized. Sequential extraction: Sequential extraction of trace elements was carried out as per Tessier et al. [5]. Drill cuttings in the amount of 1 $\mathrm{g}$ were extracted in the following order:

- Fraction 1: Exchangeable fraction: $0.11 \mathrm{M}$ acetic acid, shaking by microwaves for 7 minutes (power $20 \mathrm{~W}$ ) at $22^{\circ} \mathrm{C}$.

- Fraction 2: Fe-Mn oxide bound fraction (reducible): $0.5 \mathrm{M}$ hydroxylamine hydrochloride, $\mathrm{pH}=1.5$ shaking by microwaves for 7 minutes (power $20 \mathrm{~W}$ ) at $22^{\circ} \mathrm{C}$.

- Fraction 3: Organic bound fraction (oxidizable): 30\% hydrogen peroxide shaking by microwaves for 2 minutes (power $20 \mathrm{~W}$ ) at $22^{\circ} \mathrm{C}$, additional $1 \mathrm{M} \mathrm{ml}, \mathrm{p}^{\mathrm{H}}=2$ shaking by microwaves for 6 minutes (power $20 \mathrm{~W}$ ) at $22^{\circ} \mathrm{C}$.

- Fraction 4: Residual fraction (bound to silicates and detritus materials): Total digestion with concentrated mixture of nitric acid and perchloric acid $(3: 1 \mathrm{v} / \mathrm{v})$.

Centrifugation at $200 \mathrm{rpm}$ for $15 \mathrm{~min}$ was performed for the sake of separation after each extraction, and supernatant was taken with a pipette for analysis [6]. The content of metals in particular forms was determined through inductively coupled plasma mass spectrometry by means of ICP-OES JY 238 Ultrace (Jobin Yvon-Horriba France).

\section{Results and Discussion}

Table 1 presents total content of metals in the examined

${ }^{*}$ Corresponding author: Justyna K, Faculty of Environmental Protection Engineering, Lublin University of Technology, 40B Nadbystrzycka Street, 20-618 Lublin, Poland, Tel: +48815384410; Fax: +48815381997; E-mail: j.kujawska@ pollub.pl

Received July 05, 2017; Accepted July 12, 2017; Published July 19, 2017

Citation: Kujawska J, Cel W (2017) Mobility of Metals from Drill Cuttings. Int J Waste Resour 7: 285. doi: 10.4172/2252-5211.1000285

Copyright: (c) 2017 Kujawska J, et al. This is an open-access article distributed under the terms of the Creative Commons Attribution License, which permits unrestricted use, distribution, and reproduction in any medium, provided the original author and source are credited. 
drill cuttings sample. Among the presented analytes, the highest concentration was observed for $\mathrm{Ba}-1911.33 \mathrm{ppm}$, whereas the lowest for $\mathrm{Cd}-30 \mathrm{ppb}$. Our results indicate a similar tendency reported in the study of samples from drill cuttings piles in the United States, where barium concentration exceeded $2000 \mathrm{ppm}$. In addition, the examined samples were characterized by a high content of zinc (over $500 \mathrm{ppm})$ and lead (approximately $300 \mathrm{ppm}$ ) [7]. The waste tests were expanded by inclusion of iron and manganese, whose content in drill cuttings is of certain significance, due to their abundance in Earth's crust [8]. Manganese accumulates in coal beds, therefore, its content in certain types of coal ash amounts to $2000 \mathrm{ppm}$ [9]. Comparative analysis of drill cuttings composition is a difficult task, since it mainly depends on the employed drilling technology and the composition of utilized fluids. The concentrations of metals obtained from the study remain within permissible concentration levels in particular groups, according to the Polish Regulation of Minister of Environment on the assessment of Earth surface contamination (Journal of Laws 2016, item 1395) [10]. Barium constitutes an exception, with the concentration slightly exceeding $1500 \mathrm{ppm}$, i.e., the permissible value for category IV soil (mining areas). Barium is commonly employed in drilling, both in Poland and the USA, where it is used as a thickening agent. In drilling waste, barium is found in the form of barium sulphate, which is hardlysoluble and thus does not threaten the environment. The remaining heavy metals in drill cuttings are found in trace amounts, which therefore renders them harmless to the environment.

Table 2 presents total content of examined fractions and juxtaposed against the maximum permissible values for leached pollutants, specified in the Polish Regulation of the Minister of Environment of 18th November 2014 on the conditions of waste disposal into water or ground and on substances particularly harmful to the aquatic environment [11]. Particular attention should be drawn to the measured concentration of barium, which exceeds the permissible value for pollutants in wastewater discharged into waters or soil by the factor of four. The remaining metals are within the standards determined by Polish legal regulations. Figures 1-4 present the concentrations of metals in particular fractions 1-4. Zero emission means shift from "cradle to grave" (LCA) to "cradle to cradle".

The greatest share of exchangeable fraction was observed for $\mathrm{Mn}$ and $\mathrm{Ni}(42 \%)$, as well as for Co (36\%). Among the considered metals, the highest share of F2 fraction is found in cadmium (67\%), iron (99\%), manganese $(47 \%)$, and zinc (46\%). The share of F2 fraction in such metals as nickel, chromium, and cobalt amounts to $20 \%$. Lead and copper were the metals which were fully released in fraction 3 , barium and chromium in fraction 3 constituted $70 \%$, while, cobalt reached $50 \%$ and zinc $-40 \%$. The highest amount of metals was released in this fraction, which is characterized by medium mobility. However,

\begin{tabular}{|c|c|}
\hline Metal & Concentration [ppm] $\mathbf{S D}$ \\
\hline $\mathrm{Ba}$ & $1911.33 \pm 16.6$ \\
\hline $\mathrm{Cd}$ & $<\mathrm{n} .0$ \\
\hline $\mathrm{Cr}$ & $65.76 \pm 4.40$ \\
\hline $\mathrm{Cu}$ & $104.29 \pm 0.32$ \\
\hline $\mathrm{Ni}$ & $21.75 \pm 0.46$ \\
\hline $\mathrm{Pb}$ & $41.92 \pm 0.18$ \\
\hline $\mathrm{Zn}$ & $62.1 \pm 0.45$ \\
\hline $\mathrm{Co}$ & $0.2 \pm 0.01$ \\
\hline $\mathrm{Fe}$ & $14369.8 \pm 137.2$ \\
\hline $\mathrm{Mn}$ & $469.13 \pm 20.1$ \\
\hline
\end{tabular}

Table 1: Concentration of metals in drilling cuttings [8].

\begin{tabular}{|c|c|c|}
\hline Metals[ppm] & $\begin{array}{c}\text { Total concentrations of metals } \\
\text { from four considered fractions }\end{array}$ & $\begin{array}{c}\text { Permissible values of } \\
\text { pollutants in wastewater } \\
\text { introduced to waters or } \\
\text { soil [11] }\end{array}$ \\
\hline $\mathrm{Ba}$ & 8.24 & 2 \\
\hline $\mathrm{Cd}$ & 0.01 & 0.4 \\
\hline $\mathrm{Cr}$ & 0.08 & 0.5 \\
\hline $\mathrm{Cu}$ & 0.31 & 0.5 \\
\hline $\mathrm{Pb}$ & 0.11 & 0.5 \\
\hline $\mathrm{Ni}$ & 0.18 & 0.5 \\
\hline $\mathrm{Zn}$ & 1.66 & 2.0 \\
\hline $\mathrm{Co}$ & 0.03 & 1.0 \\
\hline $\mathrm{Fe}$ & 17.68 & $\mathrm{n} .0$ \\
\hline $\mathrm{Mn}$ & 4.41 & $\mathrm{n} .0$ \\
\hline
\end{tabular}

Table 2: Total $(I+|I+| I|+| \mathrm{V})$ concentration of metals in drilling cuttings.

Fraction I

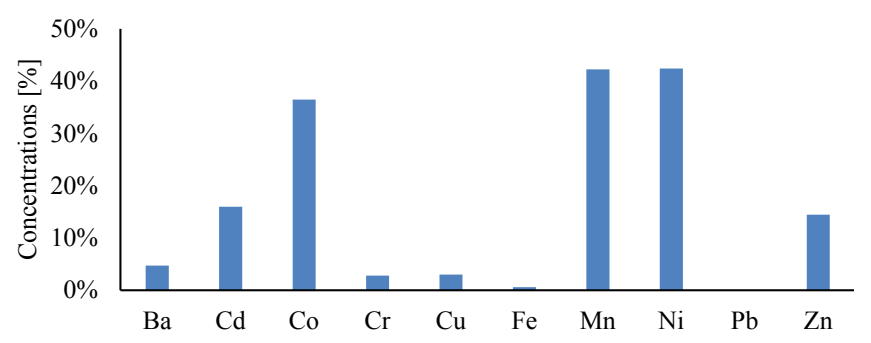

Figure 1: Percentage of metals removed from drill cuttings in BCR procedure (F1 - exchangeable), F2 - reducible, F3 - organic, F4 - residual).

Fraction II

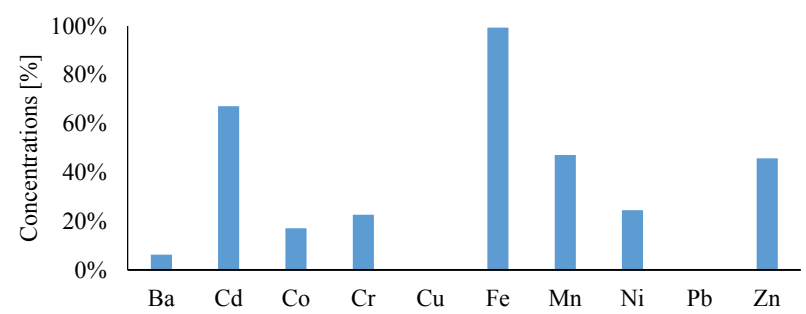

Figure 2: Percentage of metals removed from drill cuttings in BCR procedure (F2 - reducible).

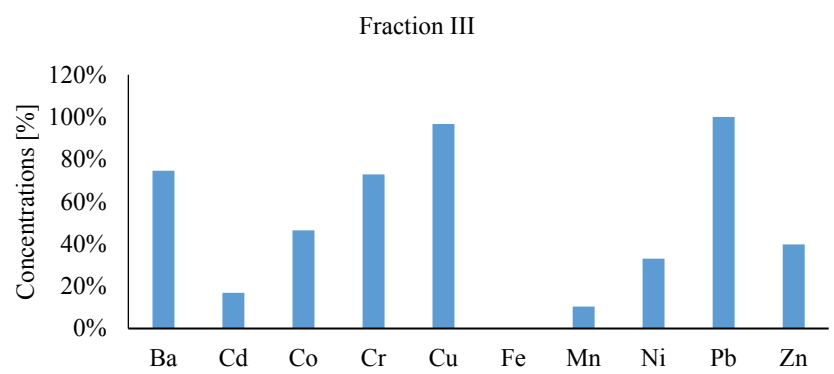

Figure 3: Percentage of metals removed from drill cuttings in BCR procedure (F3 - organic).

bioavailability of metals in this fraction changes over time. Barium was the metal with the highest share in the residual fraction, and yet was only released in $14 \%$. 


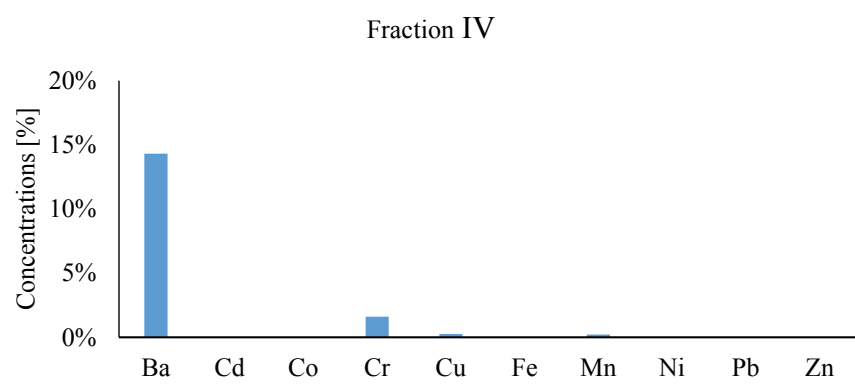

Figure 4: Percentage of metals removed from drill cuttings in $\mathrm{BCR}$ procedure (F4 - residual)

Studies showed that manganese and iron, which are components of polymer/potassium drilling fluids, are hazardous to the environment. Iron and manganese are found in abundance in the Earth's crust and constitute the most mobile elements. Their mobility changes with the weather conditions. Moreover, the impact of manganese on the environment depends on the amount of iron and loamy minerals. Drilling wastes are characterized by high content of loamy minerals (approximately 45.5\%), which may inhibit migration of manganese into the environment. Moreover, pollution of the environment by manganese is form-dependent [9]. Table 3 presents the concentration of metals in particular fractions.

Similar results of drilling waste fractionation were obtained by Stuckman. In his studies, $\mathrm{Cu}, \mathrm{Ni}, \mathrm{Zn}, \mathrm{Cd}$, and $\mathrm{Co}$ were mainly related with the oxidizable fraction. These metals exhibited the tendency for a long-term release [12].

The research conducted by Ghode showed the highest concentration of $\mathrm{Ba}$ and $\mathrm{Cr}$ in the organic fraction. However, according to the author, their activation in environmental conditions is unlikely.

Our results show certain discrepancy from the results obtained by Duel and Holliday. The studies, carried out on 31 drilling fluids, showed that such metals as $\mathrm{As}, \mathrm{Ba}, \mathrm{Cd}$, and $\mathrm{Cr}$ were found in the residual fraction, while $\mathrm{Pb}$ was found in the reducible fraction, and $\mathrm{Zn}$ in oxidizable forms [13].

The published results of research carried out by Westerlund proved that $\mathrm{Zn}, \mathrm{Cu}, \mathrm{Cd}$, and $\mathrm{Pb}$ have the highest share in the leachable fraction [14].

Results from our research and the review of literature indicate that the impact of wastes on the environment is diverse, with a broad range of impact. Simultaneously, this impact differs for each drilled well, and may result from the particular composition of drilling fluids and the geological structure in the well site.

\section{Conclusion}

The conducted study on the assessment of the content of particular heavy metal fractions in drilling wastes showed that metals are mainly bound in the organic fraction. Furthermore, metals of the organic fraction are characterized by long-term long mobility, which indicates

\begin{tabular}{|c|c|c|c|c|}
\hline $\begin{array}{c}\text { Metals } \\
\text { [ppm] }\end{array}$ & Fraction I & Fraction II & Fraction III & Fraction IV \\
\hline $\mathrm{Ba}$ & 0.39 & 0.52 & 6.15 & 1.18 \\
\hline $\mathrm{Cd}$ & 0.0008 & 0.004 & 0.0009 & 0 \\
\hline $\mathrm{Co}$ & 0.017 & 0.005 & 0.014 & 0 \\
\hline $\mathrm{Cr}$ & 0.002 & 0.019 & 0.059 & 0.001 \\
\hline $\mathrm{Cu}$ & 0.009 & 0 & 0.296 & 0.0008 \\
\hline $\mathrm{Fe}$ & 0.105 & 17.56 & 0.01 & 0 \\
\hline $\mathrm{Mn}$ & 1.86 & 2.01 & 0.46 & 0.01 \\
\hline $\mathrm{Ni}$ & 0.077 & 0.04 & 0.059 & 0 \\
\hline $\mathrm{Pb}$ & 0 & 0 & 0.11 & 0 \\
\hline $\mathrm{Zn}$ & 0.24 & 0.76 & 0.66 & 0 \\
\hline
\end{tabular}

Table 3: Concentration of various forms of the metals $\left(\mathrm{mgkg}^{-1}\right)$.

the need for constant monitoring of deposits containing this type of wastes. However, taking into account low heavy metal concentrations in frilling wastes, it appears that they do not pollute surface waters or the soil and water environment.

\section{References}

1. (2001) Regulation of the Polish Minister of Environment of 27 September 2001 on waste catalog (Dz.U.2001.112.1206) in polish.

2. Leonard SA, Stegmann JA (2010) Stabilization/solidification of petroleum dril cuttings: Leaching studies. J Hazard Mater 174: 484-491.

3. Neff JM (2010) Fate and effects of water based drilling muds and cuttings in cold water environments. Raport Prepared for Shell Exploration and Production Company Houston, Texas.

4. Fronczyk J, Radziemska M, Sygocka K (2012) Heavy metals accumulation in the pollution from road infrastructure objects. Remediation, Reclamation and Revitalization. pp: 75-83.

5. Tessier A, Campbell PGC, Bisson M (1979) Sequential extraction procedure for the speciation of particulate trace metals. Analytical Chemistry 51: 844-851.

6. Ignatowicz K, Garlicka K, Breńko T (2011) The influence of sewage sludge composting for content of chosen metals and their fractions. Inżynieria Ekologiczna 25: 231-241.

7. Breuer E, Stevenson AG, Howe JA, Caroll J, Shimmield GB (2004) Drill cutting accumulations in the Northern and Central North Sea: a review of environmental interactions and chemical fate. Marine Pollution Bulletin 48: 12-25.

8. Cel W, Kujawska J, Wasąg $H$ (2017) Impact of hydraulic fracturing on the quality of natural waters. J Ecol Eng 18: 63-68.

9. Kabata PA (2010) Trace elements in soils and plants.

10. Regulation of the Polish Minister of the Environment on the assessment of the land Surface contamination (Dz.U. 2016 poz. 1395).

11. (2014) Regulation of the Polish Minister of the Environment on the conditions to be met when introducing waste into water or ground of 18 November 2014 (Dz. U. z 2014 poz. 1800).

12. Stuckman M, Lopano CL, Hakal JA (2016) Trace metal distribution and mobility in drill cuttings from Marcellus shale gas extraction. 18th International Conference on Heavy Metals in the Environment, Ghent, Belgium.

13. Ure AM, Davidson CM (2002) Chemical speciation in the environmental. Blackwell Science, London.

14. Westerlund S, Cripps SJ (2000) Minimizing the environmental effects of drilling operations. IBC Global Conferences Limited, Aberdeen. 